\title{
Focal nodular hyperplasia and hepatocellular adenomas: What is new in 2013?
}

\author{
Elisa Palladino, Daniele Sommacale, Renaud Siboni,Christine Hoeffel, \\ Christian Lechner, Tullio Piardi, Reza Kianmanesh
}

\begin{abstract}
Introduction: The history of benign liver cell tumors, namely, focal nodular hyperplasia (FNH), and hepatocellular adenoma (HCA), has recently progressed thanks to molecular biology and imaging studies that made it possible a new classification used in European, American and East countries. Case Report: A review was performed of the numerous published articles, with focus on the management and clinical outcome of benign liver cell tumors is an attempt to promote more standardized guidelines. Conclusion: The discovery of genetic drivers of HCA has refined our knowledge of the life history of HCA from risk factors of malignant transformation. The clinical management of FNH and HCA have changed in the recent years. This will have an impact on the management of these lesions including surveillance.
\end{abstract}

Keywords: Focal nodular hyperplasia, Benign liver cell tumors (BLCT), Liver lesions, Hepatocellular adenoma

Elisa Palladino ${ }^{1}$, Daniele Sommacale $^{2}$, Renaud Siboni ${ }^{1}$, Christine Hoeffel ${ }^{3}$, Christian Lechner ${ }^{1}$, Tullio Piardi ${ }^{2}$, Reza Kianmanesh ${ }^{2}$

Affiliations: ${ }^{1}$ Department of General and Digestive Surgery, Chalons-en-Champagne Hospital, France; ${ }^{2}$ Department of General, Digestive and Endocrine Surgery, Reims University Hospital, France; ${ }^{3}$ Department of Radiology, Reims University Hospital, France.

Corresponding Author: Elisa Palladino, MD, Department of General and Digestive Surgery, Chalons-en-Champagne Hospital, 51, rue du Commandant Derrien - BP 80501, 51005 Chalons en Champagne, France; Tel:+33 (0)326696032; Fax:+33 (0)326696095; Email:palladinoelisa@hotmail.com

Received: 23 August 2013

Accepted: 30 September 2013

Published: 14 November 2013

\section{How to cite this article}

Palladino E, Sommacale D, Siboni R, Hoeffel C, Lechner C, Piardi T, Kianmanesh R. Focal nodular hyperplasia and hepatocellular adenomas: What is new in 2013? Int J Hepatobiliary Pancreat Dis 2014;4:15-25.

Article ID: 100016IJHPDEP2014

$* * * * * * * * *$

doi:10.5348/ijhpd-2014-16-RA-4

\section{INTRODUCTION}

Benign liver cell tumors (BLCT) are common and their clinical management remains controversial. The differential diagnosis of liver tumors requires understanding of the clinical and imaging features of the liver lesions $[1,2]$. A detailed history, physical examinations, hepatic tests and imaging studies are necessary for diagnosis. The use of liver biopsy, therapeutic options and follow-up are decided by the presentation of the lesion and associated patient characteristics. We present this review of literature with emphasis on the management of benign liver cell tumor with a multidisciplinary approach.

\section{FOCAL NODULAR HYPERPLASIA}

This is the second most prevalent benign liver lesion (after hemangioma), with a woman preponderance, in $80-90 \%$ of the cases, in third or fourth decade and a global incidence of about $0.6-3 \%$ of the general population. It is no identifiable etiologic factor. It is, however, associated with a conditions having local or systemic vascular anomalies. 
Focal nodular hyperplasia (FNH) has a demographic variation with a male and children of either gender preponderance in countries where oral contraceptives use has been less prevalent (i.e., China). There is not the impact on size variation from oral contraceptives use and from pregnancy and is not indispensable, though recommended, to stop oral contraceptive use [3].

Most of the patients are not symptomatic and the diagnosis is made incidentally during surgery, autopsy or imaging procedures for others symptoms. The liver function tests is normal complications, as the rupture, bleeding or malignant transformation, although rare, are described in literature [4].

The diagnosis of FNH can be made using imaging techniques in $90 \%$ of cases in experienced centers $[5,6]$. Today, surgery and biopsy are performed in some academic centers in Europe and United States for diagnosis of FNH.

Contrast-enhanced ultrasonography (CEUS) is the first modality of choice for FNH:FNH typically shows arterial increased enhancement, very marked in the first few seconds. Centrifugal (70\%) or eccentric (30\%) enhancement through one afferent correspondingly situated arteries is a diagnostic pointer.

In the portal venous phase FNH shows at least lowgrade increased enhancement in about $95 \%$ of cases. The centrifugal filling sign is very useful for diagnosis of $\mathrm{FNH}$ $[7,8]$.

Recently in 2013, Wang et al. from the University of Guangzhou (Republic of China) published their experience with CEUS in 85 patients with 85 histological proven FNH. Enhancement, centrifugal filling, spokewheel arteries were reviewed and correlated with the size. Forty-seven other focal liver lesions with contrastenhanced computed tomography (CECT) were randomly selected for comparison of diagnostic with CEUS.

The results confirm that the CECT have similar diagnostic performance for FNH (Figure 1A) and CEUS should be the first imaging technique for the diagnosis of FNH [9].

The magnetic resonance imaging (MRI) scan has the advantage of being a non-radiating technique and has the excellent contrast resolution. In MRI, a typical FNH is hyperintense in the arterial phase and isointense before contrast and in the portal venous phase (Figure $1 \mathrm{~B}-\mathrm{C}$ ).

In $89 \%$ cases, before contrast FNH is hyperintense to isointense on $\mathrm{T} 2$ and isointense to hypointense on $\mathrm{T} 1[10$, $11,12]$.

Half of FNH has a central scar, slightly hyperintense on $\mathrm{T} 2$ and with late gadolinium-contrast enhancement. However, the choice between CEUS and MRI depends upon the experience and local availability. In less than $10 \%$ of cases, the differential diagnosis of FNH, HCA and HCC cannot be solved by imaging alone. A biopsy can resolve most of these problem cases, with standard and/ or immunohistochemical staining [13, 14].

The histological diagnosis of $\mathrm{FNH}$ requires two main criteria: the lesion must be composed of benign-
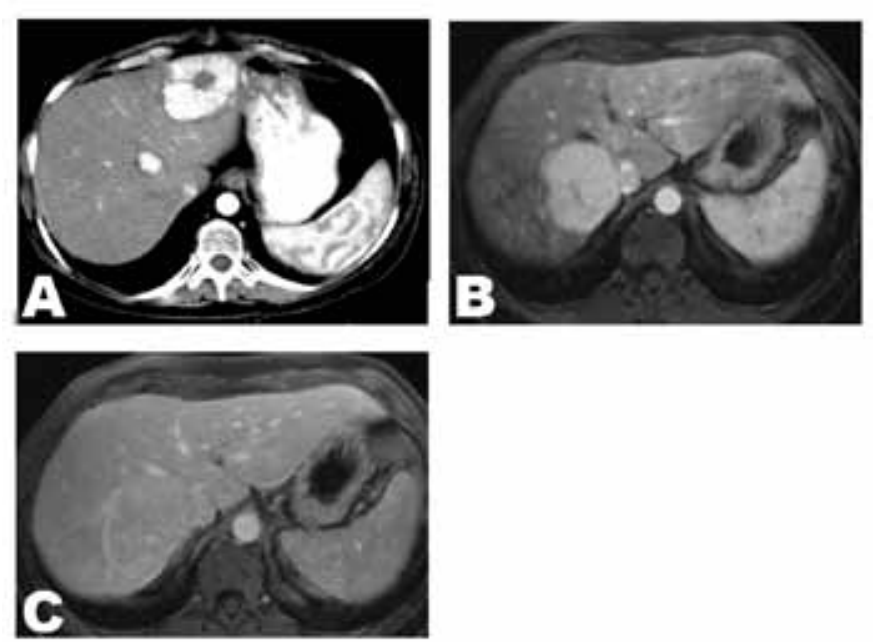

Figure 1: (A) Two Focal nodular hyperplasia in the arterial phase on computed tomogaphy scan, (B) Focal nodular hyperplasia in arterial phase after gadolinium contrast injection, (C) Focal nodular hyperplasia in portalvenous phase post gadolinium contrast injection

appearing hepatocytes and must be supplied by altered portal tracts. The risk of complications as hemorrhage and malignant transformation is absent and surgery is not indicated. However, it is still performed for organ compression, compression of liver vessels and biliary tract, pain and especially if doubt about the nature of the tumor in the absence of histological diagnosis. To date, the unavailability of guidelines hampers the follow-up of these lesions. Regarding the management and treatment of FNH, we can summarized as follow:

If the patient is female with typical FNH on imaging, normal liver tests and no medical history of cancer, the diagnosis of FNH is considered and the biopsy is not necessary.

If the patient is a male, biopsy is proposed. In the case of atypical FNH on imaging biopsy is necessary [15]. FNH is often asymptomatic and the surgery is not indicated even if the large lesion. However, the patients with a large lesions can to develop abdominal pain or compression of adjacent structures and liver resection may be indicated. Laparoscopic enucleation without coverage of the resection margins is a contemporary approach. Relating to surveillance Cherqui D [16] published a short report on clinical management of benign liver cell tumors and it is proposed for FNH monitoring by a MRI to six and twelve months, then MRI or CEUS each year for three years; after to stop monitoring [16].

\section{HEPATOCELLULAR ADENOMA}

This is an uncommon benign liver lesion arising from monoclonal proliferation of hepatocytes with a female preponderance before menopause and after a longterm use of oral contraception. It is associated with the duration and type of oral contraceptives usage. Other risk 
factors include: glycogen storage diseases and androgen intake.

Complications as hemorrhage and more rarely malignant transformation is reported [17-20].

The major classification [21] of HCA according to molecular site [21-26] divide patients with hepatocellular adenoma (HCA) in four subgroups according to their genotype/phenotype (Table 2). The first subgroup: hepatocyte nuclear factor $1 \alpha\left(\mathrm{HNF}_{1} \alpha\right)$, as the first driver gene inactived by mutation in hepatocellular adenomas and it occurs in almost exclusively all cases in females [27].

In HCA tumor cells with mutations of HNF1 $\alpha$, we described complete HNF1 a inactivation by mutation of both alleles in $35-45 \%$ of the cases and by immunohistochemitry there is a complete absence of liver fatty acid binding protein (L-FABP), specific of this subtype (Table 2) [28].

The second subgroup:mutations activating $\beta$-catenin are described in $10-15 \%$ of HCA (Table 2). CTNNB1, the gene coding for $\beta$-catenin, is the most mutated oncogene in HCC (from $20-40 \%$ of the cases). The $\beta$-catenin subtype is often associated with conditions such as glycogenosis and male hormone administration and it occurs in almost exclusively in man.
It is very important that HCA with activating mutation of $\beta$-catenin have a high risk of malignant transformation in HCC compared to other subtypes [28]. It should know that distinguishing HCA from well-differentiated HCC developed on normal liver could be challenging to diagnosis. Consequently, all patients identified with a mutation of $\beta$-catenin should be considered for liver resection to avoid the risk of malignant transformation.

The third subgroup: Hepatocellular adenomas with inflammatory features (IHCA).

Inflammatory HCA presented a cytoplasmic overexpression of SAA and CRP, two proteins of the acute phase of inflammation, in the tumor hepatocytes (Table 1) [29].

IHCA is associated frequently with high alcohol consumption and obesity, two conditions associated with chronic cytokine production and it occurs often in woman [30].

The fourth subgroup: Ten percent of HCA no identifiable etiologic factor (Table 2).

Pratical guidelines for the diagnosis of HCA subtypes are summarized in Figure 2.

Table 1: Diagnosis of FNH performed in different academic centers

\begin{tabular}{|c|c|c|c|c|}
\hline Ville & Surgery & Biopsy & Surgery & Biopsy \\
\hline \multicolumn{5}{|l|}{ French } \\
\hline Besancon & 13 & 3 & 0 & 0 \\
\hline Bordeaux & 27 & 29 & o & 2 \\
\hline Caen & 19 & 6 & o & o \\
\hline Créteil & 19 & 13 & 0 & o \\
\hline Grenoble & 3 & 12 & 0 & 1 \\
\hline Lille & 25 & 39 & 2 & 6 \\
\hline Lyon (1) & 17 & 16 & 4 & 7 (1 with HCC) \\
\hline Lyon (2) & 14 & 22 & o & 4 \\
\hline Montpellier & 15 & 25 & 3 & 1 \\
\hline Nice & 3 & 25 & 3 & 1 \\
\hline Paris (St.Antoine) & 20 & 14 & 0 & 2 (1 with $\mathrm{HCC}$ ) \\
\hline Villejuif (G.Roussy) & 5 & 6 & $\mathrm{O}$ & 4 \\
\hline \multicolumn{5}{|l|}{ International } \\
\hline $\begin{array}{l}\text { Baltimore } \\
(1984-2012)\end{array}$ & 79 & 54 & 4 & 8 \\
\hline $\begin{array}{l}\text { Brussels } \\
\text { Clinique Universitarie Saint Luc } \\
\text { (1992-2012) }\end{array}$ & 22 & 14 & & \\
\hline
\end{tabular}


Table 1: (Continued)

$\begin{array}{lll} & \text { FNH } & \text { No Final Diagnosis } \\ \begin{array}{l}\text { Heidelberg } \\ \text { (2007-2011) }\end{array} & 34 & \\ \text { London Kings } \\ \text { (1998-2011) }\end{array}$

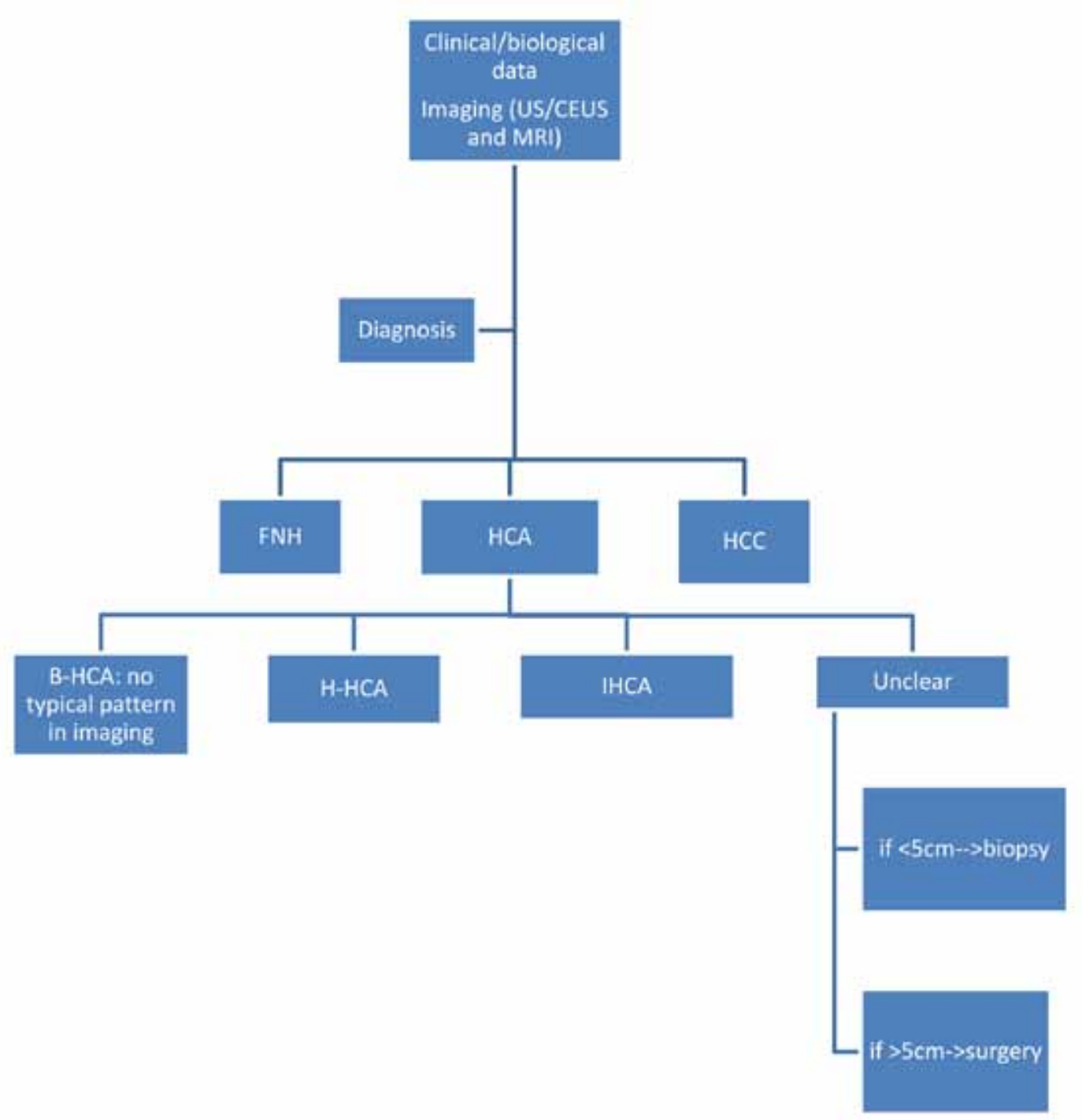

Figure 2: Criteria used for the identification of HCA subtypes (outside the emergency context)

FNH: Focal nodular hyperplasia . HCA: Hepatocellular adenoma. IHCA: Inflammatory Hepatocellular Adenoma. H-HCA: Adenomas inactived for HNF1A. B-HCA: B-Catenin activated adenomas. 


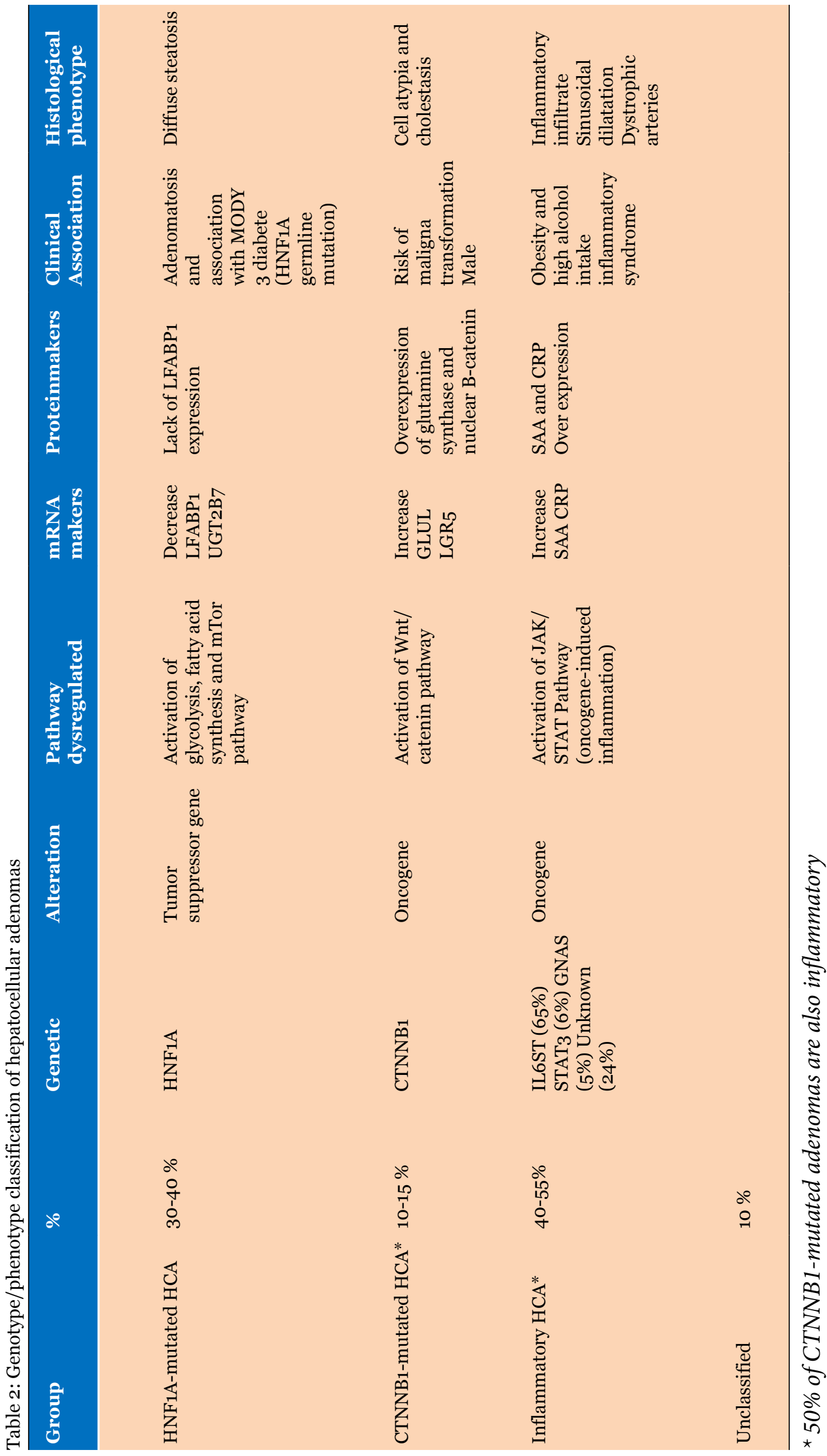


Once the diagnosis of liver tumor is made, the patient is often referred to a surgeon (Figures 3 and 4). The identification of subtypes is one of the key factors among others that need to be collected.

There are neither specific guidelines nor a standardized therapeutic approach available to date to its management [31-33].

However, there is a consensus according to the HCA $>5 \mathrm{~cm}$ should be resected if they have not regressed after stopping oral contraceptives, particularly those at a high risk of malignant transformation ( $\beta$-HCA and $\beta$-IHCA) (Figure 4).

Some surgeons prefer that all HCA should be removed particularly, if they are easily accessible laparoscopically [34-36].

Balabaud $\mathrm{C}$ et al. from the University of Bordeaux, reviewed their experience and suggested the management of HCA subtypes $<5 \mathrm{~cm}$ as it is summarized in Table 3 (Figure 5) [31].

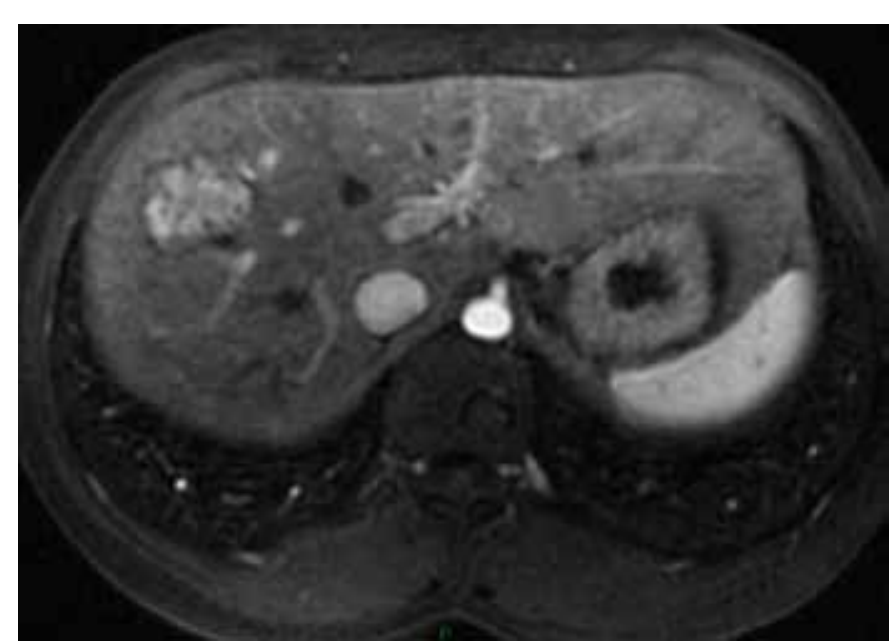

Figure 3: Hepatocellular adenoma arterial phase on magnetic resonance imaging.

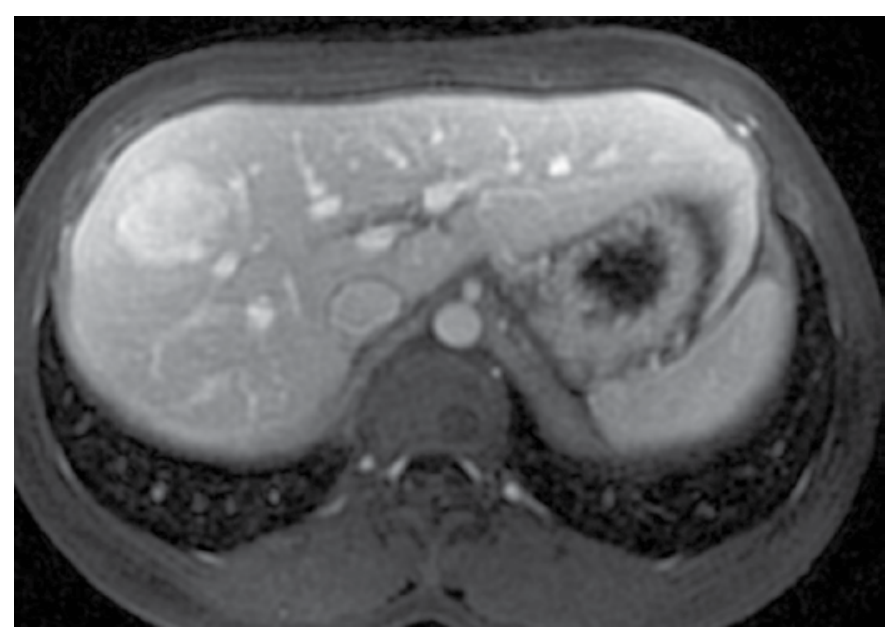

Figure 4: Hepatocellular adenoma portovenous phase on magnetic resonance imaging.
They proposed in female patients, if size increases after follow-up and to stop oral contraceptive, resection if the size of lesion is $>5 \mathrm{~cm}$, though the resection should be considered for nodules $<5 \mathrm{~cm}$ (in the $3-4 \mathrm{~cm}$ range) and resection independently of the size in the male. A biopsy is very performed in patients at risk of malignant transformation such as young woman/metabolic or vascular disorders. In presence of patients with $\mathrm{H}-\mathrm{HCA}$ associated to abnormal genetic counseling resection should be considered independently of the size.

Future development will be based on imaging techniques, molecular data including chromosomal abnormalities, in the hope of being able to combine molecular, radiological and clinical data.

Table 3: Clinical and pathological information useful to manage the patient (Balabaud et al. 2013)

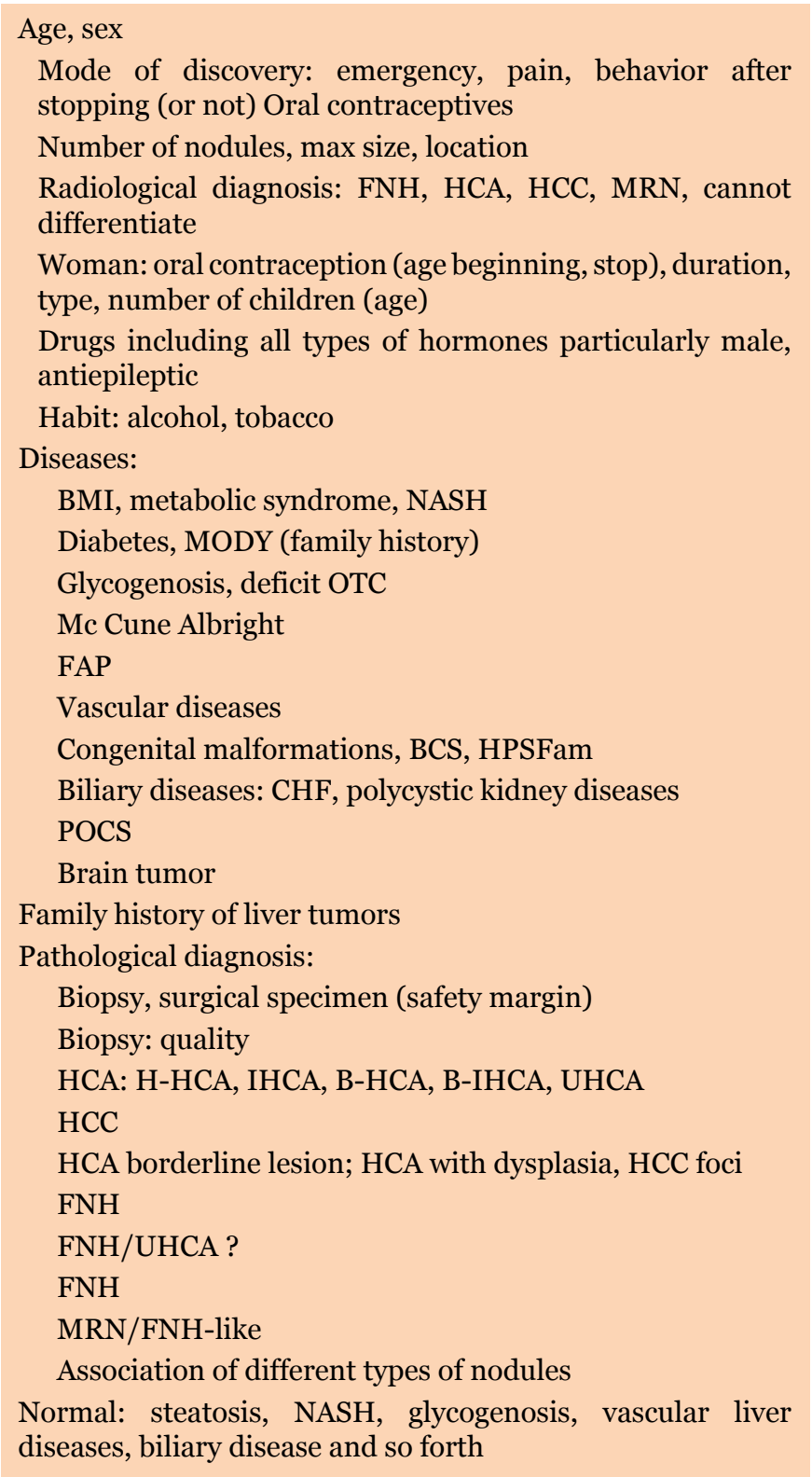




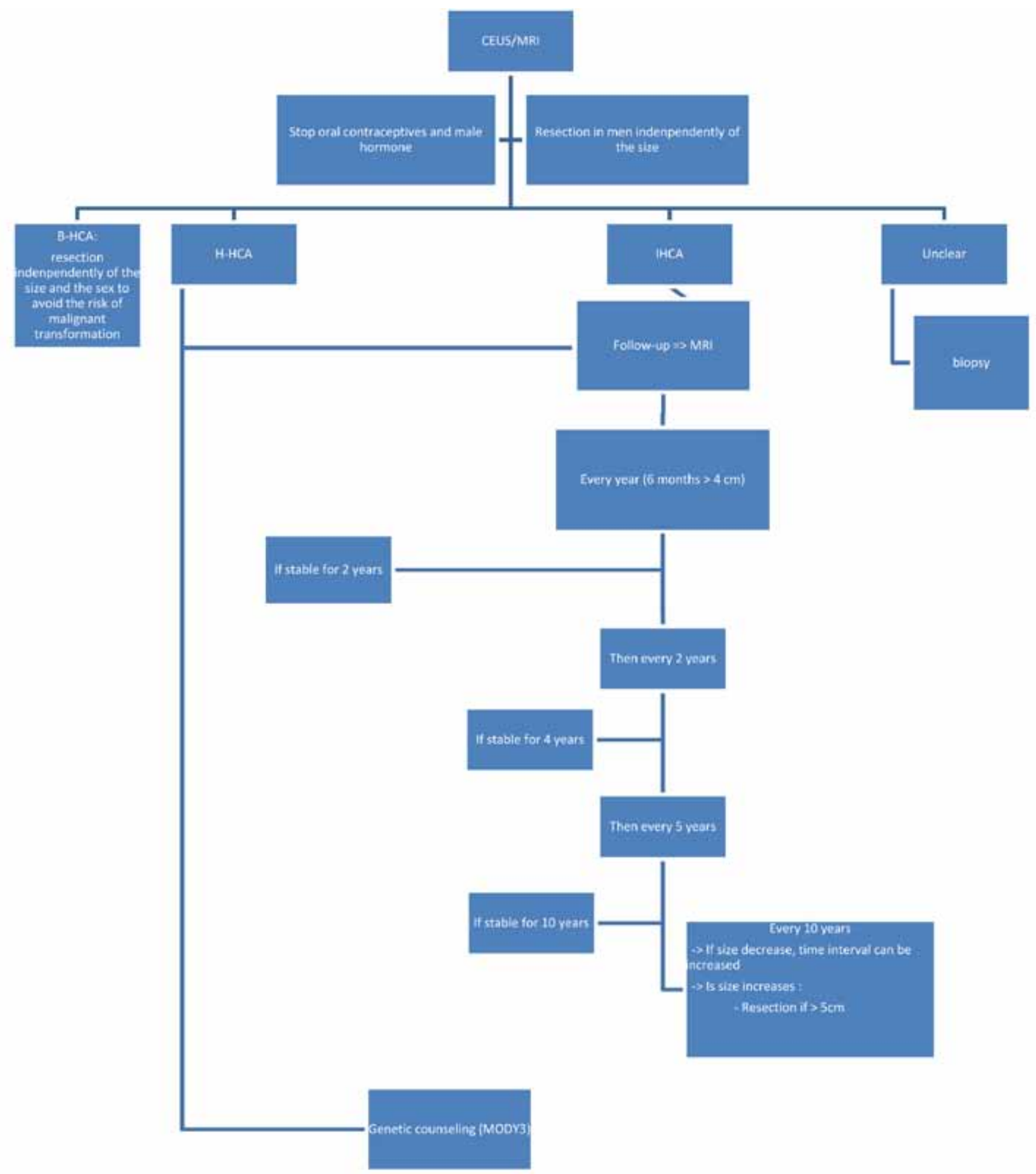

Figure 5: Management of HCA subtypes $<5 \mathrm{~cm}$

$\mathrm{Pa}$ - Patients overweight/obese/with metabolic syndrome (the majority with IHCA) should be followed

In presence of multiple HCA nodules: generally all nodules are of the same subtype (i.e., H-HCA, IHCA) Among IHCA some may be B-catenin mutaded, others not. Association of H-HCA and IHCA has been rarely observed in a same liver. In glycogenosis, different types of nodules may exist (B-HCA, IHCA, B-IHCA and UHCA). The destruction (resection, radio frequency) of nodules depends on the size, on the presence of B-catenin mutation and on the disease background. OLT is exceptional and should not be considered just on the number criteria.

MODY 3: maturity onset diabetes of the young type 3, GS: glutamine synthetase 


\section{CONCLUSION}

In future, we will be able to propose a specific guideline which can be a multidisciplinary approach (hepatologist, surgeon, radiologist and pathologist) towards the overall management of these diseases and is key factor for a good outcome.

$* * * * * * * * *$

\section{Author Contributions}

Elisa Palladino - Substantial contriutions to conception and designs, Acquisition of data, Drafting the article, Revising it critically for important intellectual content, Final approval of the version to be published

Daniele Sommacale - Substantial contriutions to conception and designs, Acquisition of data, Drafting the article, revising it critically for important intellectual content, Final approval of the version to be published Renaud Siboni - Substantial contriutions to conception and designs, Acquisition of data, Drafting the article, Revising it critically for important intellectual content, Final approval of the version to be published Christine Hoeffel - Substantial contriutions to conception and designs, Acquisition of data, Drafting the article, Revising it critically for important intellectual content, Final approval of the version to be published

Christian Lechner - Substantial contriutions to conception and designs, Acquisition of data, Drafting the article, Revising it critically for important intellectual content, Final approval of the version to be published Tullio Piardi - Substantial contriutions to conception and designs, Acquisition of data, Drafting the article, Revising it critically for important intellectual content, Final approval of the version to be published

Reza Kianmanesh - Substantial contriutions to conception and designs, Acquisition of data, Drafting the article, Revising it critically for important intellectual content, Final approval of the version to be published

\section{Guarantor}

The corresponding author is the guarantor of submission.

\section{Conflict of Interest}

Authors declare no conflict of interest.

\section{Copyright}

(C) Elisa Palladino et al. 2014; This article is distributed under the terms of Creative Commons attribution 3.0 License which permits unrestricted use, distribution and reproduction in any means provided the original authors and original publisher are properly credited. (Please see www.ijhpd.com/copyright-policy.php for more information.)

\section{ABBREVIATIONS:}

US: Ultrasound

MRI: Magnetic resonance imaging

CEUS: Contrast-enhanced ultrasound

NFH: Nodular focal hyperplasia

HCA: Hepatocellular adenoma

NRH: Nodular regenerative hyperplasia

BLT: Benign liver tumour

HCC: Hepatocellular Carcinoma

CT: Computed Tomography

OC: Oral contraceptives

GS: Glutamine synthetase

CRP: C-reactive -protein

IHCA: inflammatory adenomas

\section{REFERENCES}

1. Bonder A, Afdhal N. Evaluation of liver lesions. Clin Liver Dis 2012 May;16(2):271-83.

2. Mezhir JJ, Fourman LT, Do RK, et al. Changes in the management of benign liver tumours: An analysis of 285 patients. HPB (Oxford) 2013 Feb;15(2):156-3.

3. Mathieu D, Kobeiter $\mathrm{H}$, Maison $\mathrm{P}$, et al. Oral contraceptive use and focal nodular hyperplasia of the liver. Gastroenterology 2000;118(3):560-4.

4. Mneimneh W, Farges O, Bedossa P, Belghiti J, Paradis V. High serum level of alpha-fetoprotein in focal nodular hyperplasia of the liver. Pathol Int 2011;61(8):491-4.

5. Vilgrain V. Focal nodular hyperplasia. Eur J Radiol 2006;58(2):236-45.

6. Lewin M, Vilgrain V. Radiological diagnosis of benign liver cell tumors. Gastroenterol Clin Biol 2008 Mar;32(3):304-9.

7. Leen E. The role of contrast-enhanced ultrasound in the characterisation of focal liver lesions. Eur Radiol 2001;11 Suppl 3:E27-34.

8. Jang HJ, Yu H, Kim TK. Contrast-enhanced ultrasound in the detection and characterization of liver tumors. Cancer Imaging 2009 Nov 6;9:96-103.

9. Wang W, Chen LD, Lu MD, et al. Contrast-enhanced ultrasound features of histologically proven focal nodular hyperplasia: Diagnostic performance compared with contrast-enhanced CT. Eur Radiol 2013;23(9):2546-4.

10. Asbach P, Klessen C, Koch M, Hamm B, Taupitz M. Magnetic resonance imaging findings of atypical focal nodular hyperplasia of the liver. Clin Imaging 2007 Jul-Aug;31(4):244-52.

11. Fowler KJ, Brown JJ, Narra VR. Magnetic resonance imaging of focal liver lesions: Approach to imaging diagnosis. Hepatology 2011 Dec;54(6):2227-37.

12. Albiin N. MRI of Focal Liver Lesions. Current Medical Imaging Reviews 2012;8:107-16.

13. Balabaud C, Al-Rabih WR, Chen PJ, et al. Focal Nodular Hyperplasia and Hepatocellular Adenoma around the World Viewed through the scope of the Immunopathological Classification. International Journal of Hepatology 2013;2013:268625. 
14. Bioulac-Sage P, Cubel G, Taouji $S$, et al. Immunohistochemical markers on needle biopsies are helpful for the diagnosis of focal nodular hyperplasia and hepatocellular adenoma subtypes.The American Journal of surgical Pathology 2012 Nov;36(11):16919.

15. Fabre A, Audet P, Vilgrain V, et al. Histological scoring of liver biopsy in focal nodular hyperplasia with atypical presentation. Hepatology 2002;35:41420.

16. Cherqui D. Clinical Management of benign liver cell tumors. Gastroentérologie Clinique et Biologique 2008 Mar;32(3):310-3. [Article in French].

17. Barthelmes L, Tait IS. Liver cell adenoma and liver cell adenomatosis. HPB (Oxford) 2005;7(3):186-96.

18. Deneve JL, Pawlik TM, Cunningham S, et al. Liver cell adenoma: A multicenter analysis of risk factors for rupture and malignancy. Annals of Surgical Oncology 2009 Mar;16(3):640-8.

19. Farges O, Ferreira N, Dokmak S, Belghiti J, Bedossa P, Paradis V. Changing trends in malignant transformation of hepatocellular adenoma. Gut 2011 Jan;6o(1):85-9.

20. Seo JM, Lee SJ, Kim SH, Park CK, Ha SY. Hepatocellular carcinoma arising from hepatocellular adenoma in a hepatitis B virus-associated cirrhotic liver. Clinical Radiology 2012 Apr;67(4):329-3.

21. Zucman-Rossi J, Jeannot E, Nhieu JT, et al. Genotype-phenotype correlation in hepatocellular adenoma: new classification and relationship with HCC. Hepatology 2006 Mar;43(3):515-24.

22. Bioulac-Sage $\mathrm{P}$, Rebouissou S, Thomas $\mathrm{C}$, et al. Hepatocellular adenoma subtype classification using molecular markers and immunohistochemistry. Hepatology 2007 Sep;46(3):740-8.

23. Rebouissou S, Bioulac-Sage P, Zucman-Rossi J. Molecular pathogenesis of focal nodular hyperplasia and hepatocellular adenoma. J Hepatol 2008;48:16370.

24. Bioulac-Sage P, Laumonier H, Couchy G, et al. Hepatocellular adenoma management and phenotypic classification: The Bordeaux experience. Hepatology 2009 Aug;50(2):481-9.

25. Nault JC, Zucman Rossi J. Molecular Classification of Hepatocellular Adenomas. International Journal of Hepatology 2013;2013:315947.

26. Nault JC, Bioulac-Sage P, Zucman-Rossi J. Hepatocellular benign tumors-from molecular classification to personalized clinical care. Gastroenterology 2013 May,144(5):888-902.

27. Bluteau O, Jeannot E, Bioulac-Sage P, et al. Bi-allelic inactivation of TCF1 in hepatic adenomas. Nature Genetics 2002 Oct;32(2):312-5.

28. Lagana SM, Salomao M, BaoF, Moreira RK, Lefkowitch JH, Remotti HE. Utility of a immunohistochemical panel consisting of glypican-3, heat-shock protein70 , and glutamine synthetase in the distinction of lowgrade hepatocellular carcinoma from hepatocellular adenoma. Appl Immunohistochemistry Molecular Morphology 2013 Mar;21(2):170-6.

29. Sa Cunha A, Blanc JF, Lazaro E, et al. Inflammatory syndrome with liver adenomatosis: The beneficial effects of surgical management. Gut 2007;56(2):3079.
30. Paradis V, Champault A, Ronot M, et al. Telangiectatic adenoma: an entity associated with increased body mass index and inflammation. Hepatology 2007 Jul;46(1):140-6.

31. Bioulac-Sage P, Balabaud C, Zucman-Rossi J. Focal nodular hyperplasia, hepatocellular adenomas: Past, present, future. Gastroenterol Clin Biol. 2010 AugSep;34(6-7):355-8.

32. Buell JF, Tranchart H, Cannon R, Dagher I. Management of benign hepatic tumor. Surg Clin North Am 2010 Aug;90(4):719-35.

33. Fonseca S, Hoton D, Dardenne S, et al. Histological and Immunohistochemical Revision of Hepatocellular Adenomas: A Learning Experience. International Journal of Hepatology 2013;2013:398308.

34. Ardito F, Tayar C, Laurent A, Karoui M, Loriau J, Cherqui D. Laparoscopic liver resection for benign disease. Arch Surg 2007;142:1188-93.

35. Dokmak S, Raut V, Aussilhou B, et al. Laparoscopic left lateral resection is the gold standard for benign liver lesions: A case-control study. HPB (Oxford) 2014 Feb;16(2):183-7.

36. Dokmak S, Paradis V, Vilgrain V, et al. A single-center surgical experience of 122 patients with single and multiple hepatocellular adenomas. Gastroenterology 2009 Nov;137(5):1698-705. 


\section{ABOUT THE AUTHORS}

Article citation: Palladino E, Sommacale D, Siboni R, Hoeffel C, Lechner C, Piardi T, Kianmanesh R. Focal nodular hyperplasia and hepatocellular adenomas: What is new in 2013? Int J Hepatobiliary Pancreat Dis 2014;4:15-25.

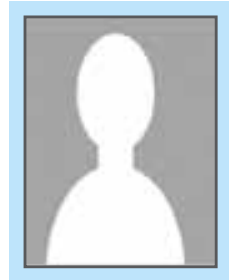

Elisa Palladino is Resident at Department of General and Digestive Surgery of Chalons-en-Champagne Hospital, France. Her area of interest include liver surgery, gastrointestinal surgery, minimally invasive abdominal surgery. She has published research papers in national and international academic journals.

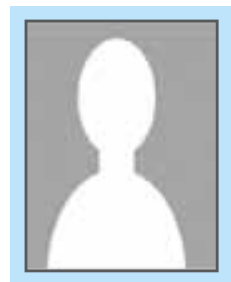

Daniele Sommacale is Professor at Department of General and Digestive Surgery, University of Reims, School of Medecine, France. His area of interest include hepatobiliary surgery and liver transplantation. He has published research papers in national and international academic journals and authored books.

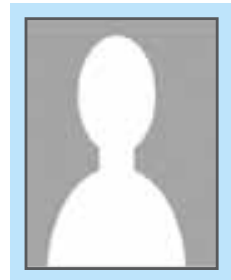

Renaud Siboni is Resident at Department of Surgery, University of Reims, France. His area of interest include general surgery.

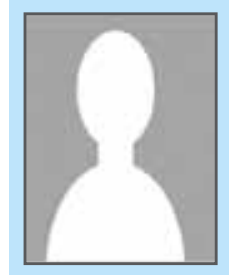

Christine Hoeffel (MD, PhD), She is Professor of Radiology at the University hospital of Reims, France. She has published or co-published over 100 papers, mainly focused on abdominal imaging and magnetic resonance imaging.

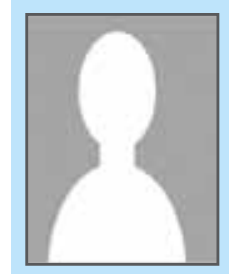

Christian Lechner is Chief Resident at Department of General and Digestive Surgery of Chalons-enChampagne Hospital, France. His area of interest include gastrointestinal surgery, minimally invasive abdominal surgery.

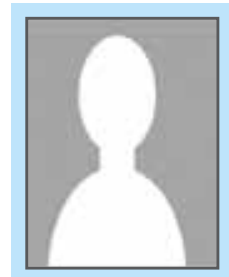

Tullio Piardi is Resident at Department of General and Digestive Surgery, University of Reims, School of Medecine, France. His area of interest include liver and pancreatic surgery, gastrointestinal surgery. He has published research papers in national and international academic journals.

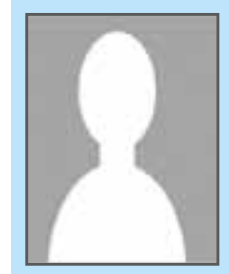

Reza Kianmanesh is a Professor at Department of General and Digestive Surgery, University of Reims, School of Medecine, France. His area of interest include hepatobiliary and pancreatic surgery, liver transplantation, gastrointestinal surgery. He has published research papers in national and international academic journals and authored books. 
Access full text article on

other devices

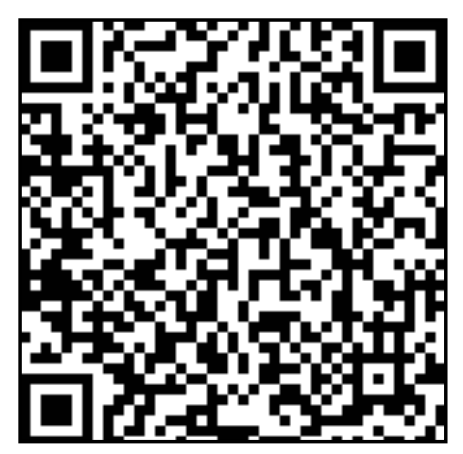

Access PDF of article on other devices

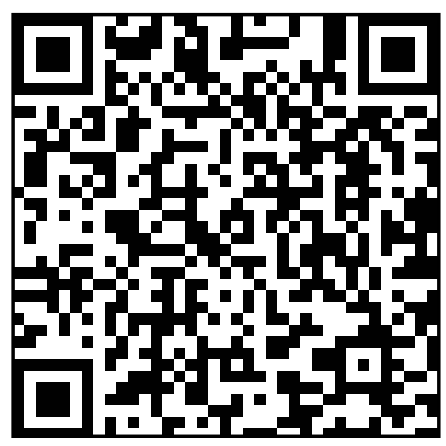

